\title{
New Concept in Automotive Manufacturing: A System-based Manufacturing
}

\author{
Mohammad A. Omar \\ Clemson University-International Centre for Automotive Research CU-ICAR
}

USA

\section{Introduction}

The automotive industry has been going through a continuous process of adjustment due to the changes in its operating environment. Such factors; the govremental in addition to the National Standards Setting Bodies NSB's regulations, for example the Corporate Average Fuel Economy CAFE standards controls the OEMs fleet fuel economy average, leading to the introduction of smaller vehicles or the use of light weight materials (low density) in the vehicle structures. In addition to the new environmental regulatons that have led to changes in the material usage, the levels of production emissions, and the expended energy. Additionally the NSB's have different focus in different countries so for OEMs operating in different markets, they would have to respond to different regulations; for example the NSB's in Eruope such as the DIN (German Institute for Standardization) and the CEN (The French Creative Environmental Network) have a recent focus on safety systems and standards in automobiles, while the american NSB's such as American National Standards Institute ANSI focuses on the final vehicle testing protocoles. All these regulations have a direct effect on the automotive manufatuirng; to provide specific exmaple; the automotive OEMs have shifted their paint from the typical solventborne into waterborne paints, due to the Volatile Organic Compounds VOCs emissions. This shift led to additional production steps, such as the flash off zone which is necessary to control the amount of water evaporation from the paint once it is applied on the vehicle shell. Also, the waterborne paint requires tigher control over the spray booth air conditioning requirements, whih have led to more energy usage in the paint area. Another effect on the manufacturing came from the use of the Tailor Welded Blanks, Coils and Tubes TW B/C/T technology which is introduced to allow designers to custom mix different steel grades or panel thicknesses for some body panels to meet the different functional requirements (load-bearing vs. Non-load bearing) across the panel; a good example of the TWB is the door inner panel which has a stiffness requirement at the hinge area, hence thicker or stronger steel is used in that area while the rest of the panel is non-load bearing structure, which means that a thinner or weaker steel grade can be used. The TWB technolgy enabled the designers more freedom to met fucntionalities and save weight at the same time, however this technology have added several steps such as laser welding different pieces to from the new blank, which also require stacking and de-stacking steps; more importantly if the OEMs don't have enough 
epxertise in laser welding then such blanks will need to be shipped to the subcontrator location; adding more time delays and cost implications. Ultimately, each OEM will have to conduct a feaisbility study to assess the TWB technology benefits and challenges, before impelmenting such appraoch. Other impacts on manufacturing include; the role of the ergonomics on the design of the final assembly area and the usage of the different fixture and power-tool hardware to help the line workers in thier frequent activities. Also the ergonomic have a played a major role in the design of the conveyor systems.

Other external factors include, the customer demand trends, which have changed to be more diverse in trems of product type and its power-train propulsion. These days, the OEMs will have to depart from the economy of scope perspective and focus on more economies of scope in terms of their product portfolio. To provide a quantitative example; the Japanese OEMs produced 85 different models in 1960's, which is further increased into 400 models in the 1980's; at the same time the production volume per model kept decreasing, hence the OEM is producing the same umber of vehicles but with a higher product mix; meaning that the automotive manufacturing is shifting from high volume, low mix production strategy into a high volume, high mix, which have major impacts on the factory layout; shifting from the product type layout strategy where the processes and machinery are ordered and sequneced based on a known, repeatable product type with the goal of decreasing the product lead time; into the process and cell based layouts. The process and cell based layouts are better suited for higher product mix because it was designed to increase the manufactuirng flexibility to deal with varying product. Additionally, the change in customer demand is not only limited to vehicles with different body style, size, or platform, but also in terms of the product propulsion or power-train system; internal combustion engine (gasoline or diesel), or internal combusion engine assisted with a recchargeable battery system (hybrid), or a full electric vehicle. These variations in power-train complicates the manufacturing final assembly process due to the different power-train mariage steps required for each type, in addition to the different steps needed to assemble each of these sub-assemblies and of course the associated saftey considerations when dealing with fully charged battery packs.

The manufacturing operating cost is another challenge affecting the automotive OEMs. The operating cost is changing in terms of the raw material cost, which can be qunatified into vehicle structural materials mainly Steel and Aluminium in addition other materials including the trim material and the chemicals such as paint, wax, adheisves and sealants. Another issue with the operating cost is the relative cost of energy between the different countries; for example the electric energy consumption in Italy costs around 30 cents for each kWhr, compared with 10 cents in Germany, and 5 cents in South Africa. The energy cost not only affect the direct manufacturing energy expenditures but also affect the cost of raw materials, because of the intensive material extraction energy requirements; for example the to extract and process $1 \mathrm{~kg}$ of wrought Aluminium almost $60 \mathrm{kWhr}$ are expended. Also, the labor wage cost is highly relative between the different countries; to illustrate with an example, the labor wage is South Africa is around $\$ 5 / \mathrm{hr}$ compared with more than $\$ 30 / \mathrm{hr}$ in the United States.

The emerging of new markets and more distributed production and supply networks have also challenged the automotive industry and affected their production strategies. This factor is further exagerated with the penetration of new Original Equipment Manufacturers OEMs into established markets such as the Korean and Chinese OEMs. These factors have 
impacted the vehicle manufacturing because, the new markets introduced new challenges in identifying a supplier base if the production is established in such markets, and maintaining the labor force for long time periods while other OEMs are trying to recriut the same labor force. To illustrate this point with an example, the avergae age for a team-leader working for an automotive OEM in Japan is around 35-40 years, while that for the same OEM in China is around 30 years. Further complications are the result of govermental monitoring regulations and Intellectual Property IP issues.

\section{The current state of automotive manufacturing}

The automotive manufacturing systems in its three perspectives; the procedural side, the static/structural (machinery) side, and the transformational (material conversion processes) side, have been affected due to the above changes and challenges. To provide specific examples; the oil crisis in the 1970s have led to dramatic loss in customer proudct usage, hence halted the automotive production lines. In 1980's, the entering of the East Asian OEMs with their manufacturing practices into the established markets of Europe and North America, forced the industry to change and adjust its operational side. Such changes included more seious adoption of the lean manufacturing and the value engineering practices into the automotive manufacturing systems; within the American and the European OEMs. This is apparent in the emergence of the company-wide specific production systems such as the Ford Prdouction System FPS, the Mercedes Benz Production System MPS which are built on the same pillars as the Toyota Production System TPS. In addition to changes in the forecasting and the Material Requirement Planning MRP practices and the departure from the mass-production practices; or push systems into the pull based systems, where the customer demand in terms of quantity and frequency decides on the production output. Additional adjsutments were in the static side, where several OEMs started to follow a celluar based production layouts to accomodate the assembly and the fabrication of the vehicle sub-assemblies.

However, such practices did not affect the transformational side in any meaningful way; so the actual manufacturing processes from stamping to body-weld and then painting stayed the same since the 1970's. Such processes not only control the production lead time and cost but also the research and development efforts required to develop the different jigs and fixtures in addition to the stamping dies, which cost the automotive OEM around \$5 million per die and around 2 years for the development and the approval processes. Additionally, the actual fabrication processes governs and control the overall flexibility in terms of product volume and scope. Furthermore, the current and coming challenges of added environmental regulations, the wide variations in customer demand in terms of product type (vehicle platforms) and volume can only be met through adjusting the manufacturing processes into more dedicated yet flexible platforms. Additional motivation to adjust and change the existing transformational processes, is due to the increase in demand for light weight vehicles that features hybridized body materials from Aluminum, Magnesium and Adavnced High Strength Steels AHSS. Forming and fabricating such new materials onto the current production lines introduces several technical challanges due to these materials intrinsic propoerties. For example, forming Aluminum using mechanical or hydraulic presses is not trivial due to its narrower forming window and its higher springback levels when compared with steel; this have forced several OEMs to design new body structures based on the space-frame design not the standard uni-body platform. However, the space- 
frame is based on extrusions and hydroformed components focring the OEMs to rely on external suppliers for such components in addition the space-frame designs can't be accomodated on mass production basis due to the high level of manual work content involved. Furthermore, with a space-frame platform, it is more difficult for OEMs to selectively incorporate other lower cost materials to provide improved functionalities at lower cost.

So this chapter is intended to highlight some of the potential transformational changes that can be incorporated to change the current manufacturing practices into more streamlined and dedicated platforms that not only consolidate the number of components but also the number of processes involved in making the vehicle body structures. So this chapter is mainly focused on the transformational processes utilized in the automotive assembly plants.

\section{The automotive manufacturing transformational processes}

The current automotive manufacturing processes can be mainly perceived from the assembly operations which lead to the construction of the complete vehicle structure; and the power-train operations which are responsible for fabricating the power-train and driveline components. The assembly processes starts with the stamping and forming of the vehicle body sheet panels into the vehicle different structures, using a variety of mechanical and hydraulic presses and dies. The stamped body-parts are then joined to form the vehicle main sub-assemblies that include the under-body sub-assembly, the side members (left and right) sub-assembly also, the fractional sub-assemblies that include; the roof, the cowl, the upper and lower backs, and the engine compartment sub-assembly. Other stamped componenets are called the vehicle closures namely; the doors, trunk, fenders, and the hood. The joinng porcess features an army of robots that join the $\sim 500$ stamped components to form the vehicle body shape using a around 5000 spot welds, several meters $(\sim 2 \mathrm{~m})$ of Metal Inert Gas MIG welds, and around 10-20 meters of adhesive bonding. Each of these joining technologies is applied based on each body location functionality (stiffness) and styling requirement requirements (surface finish). The spot welded are applied using electordes with different tip material and diameters, and using different combination of welding current and time to accomodate the different material types and thicknesses; even though the spot welding is a very effective joining process it still requires a two-side access for each joint which limits its application for certian locations within the vehicle. On the other hand, the MIG welding can be applied from one side, but results in a larger heating foot-print leading to a larger Heat Affected Zone HAZ around the weld. Additionally the MIG welding process requires a shielding gas environment to protect the welding pool from any contamination or oxidations, which might ultimately lead to a weaker weld. The adhesive bonding has been typically applied to join the inner and outer panels of doors and hoods, after it is hemmed. The adheisve bonding is gaining more acceptances within the automotive industry due to its added advantages, such as its ability to join dis-similar materials whicl alow the OEMs to join Aluminum and Steel without worrying about the differences in thermal characteristics (thermal expansion coefficient, melting point, etc) or the galvanic corrosion issue. At the same time, the adheisve bonded joints are stiffer than the spot welded ones, due to the fact that the joint is made up of folded material, which increases its moment of inertia hence increasing its stiffness. On the other hand, the adhesive 
bonding should be selected carefully to ensure its compatability with the production conditions such as the curing oven temperatures, and the chemicals in the immersion paint tanks such as the E-Coat and the cleaning tanks. Additionally, the adheisve material should be checked for its comptability with the vehicle service life conditions, to avoid any toxic emissions or degradation in the adhesive performance.

Following the joining process in the body-shop area, the vehicle structure which is called the Body in White BiW at this stage, starts the painting process, which conditions, cleans, and convert the BiW surfaces to provide it with a corrosion resistance finish and prepare it for the sub-sequent spray painting steps. The spary paint covers the vehicle structure with three to five coats composed of the primer, the top-coat or base-coat and finally the clear coat. These coats provide not only a corrosion resistance, and a chip resistance layer but also the vehicles' final asthetics. The final assembly area then installs the different trim parts into the vehicle shell and joins the shell with the power-train, to complete the vehicle build. The final assembly area features mainly manual work assisted with power-tools.

The power-train manufactuirng sequence is composed of a variety of casting, forging processes to form the engine cylinder blocks and head, the connecting rods, the cam and crank shafts. These processes are then followed by multiple machining steps to remove excess material, drill functional holes, and create the required surface roughness. The final assembly of the engine and transmission components is done manually with the aid of different fixtures and fault-proof jigs. The power-train plants rely mainly on in-house components, however the assembly plants receives more material content from the different suppliers. It is important to mention that the power-train plant and the assembly plant are sequenced to follow the same production takt-time, hence at the end of the day each produced engine will meet with a specific body-shell in the final assembly area to output a complete vehicle following one unified takt-time.

Following text tries to highlight the main challenges and shortcomings of the current automotive assembly manufacturing processes and steps;

- Having the stamping process right at the begining with a rigid die shape that can not be changed, locks the shape of the vehicle shell early on in the manufacturing process, hence it does not allow the OEM to operate based on make to order principles. The only thing that the OEM can change is the final color of the vehicle shell in addition to some of the trim options because such operations are done late in the process.

- $\quad$ The stamping process yields around 400-500 parts and pieces that need to be joined and assembled which results in large number of processing steps in addition to even larger number of non-value added efforts in stacking, de-staging, staging, and transporting tasks. In addition stamping this large number of pieces requires more dies and adds more complexity to the sequencing and the allocation between/of the different presses and press lines.

- $\quad$ The reliance on the stamping to form the body shell, limits the OEMs material choices and the final shapes and geometries. For example the formability of light weight materials such as Magnesium and Aluminium limits the bending radius to the panel thickness ratio, which can be achieved using a press based forming. So, Aluminium can only be stamped into flat or semi-flat panels such as the hood or the roof. Furthermore the stamping process does not allow the designers to manipulate the cross sectional shape freely to help compensate for the Aluminium lower stiffness from that of Steel. 
- The stamping dies not only lock the vehicle shell early in the manufacturing process, but also through the product life, for example a typical vehicle model life is around 4-5 years. However if the vehicle model life is shortened due to low vehicle acceptance or other economical conditions, then the OEM will incur heavy losses due to the high development cost already paid for each major die. At the same time some "face lift" redesign can be done but it will be limited to only one aspect of the vehicle overall geometry.

- Each one of the manufacturing processes within the assembly plant is different in its drivers and sensitivities. For example the stamping process is driven by the material (sheet metal) and the machinery (presses), while the joining process is heavily dependent on the machinery (robotic welders), the painting process is dependent on the paint material and the booth conditions and controls. While the final assembly area is heavily dependent on manual work so it's mainly controlled by the labour productivity and attitude (absenteeism). Hence these processes are not integrated but merely set in a serial fashion to apply different values to the vehicle semi-finished components as it travels through the production line. This adds greater complexity to the control and the monitoring schemes used to synchronize it. In addition this renders the overall production system sensitive to variety of market factors. The Toyota Production System tried to resolve the laakc of integration between the different production stages using the Andon system to highlight any problem areas within the production line, along with the Kanban system to synchronize the one-piece flow between the different stations. However, these systems are effective for known product type and quantity hence it need to be adjusted and changed to add more flexibility to the production sequence.

- The current joining process is composed of around 5000 spot welds per vehicle, which adds more lead time in addition it adds more investment in machinery, because applying 5000 spot welds within a typical takt time of 60 seconds means more robotic welders. Additionally, the high frequency of the welding process translates into more intensive maintenance efforts, especially for dressing and changing the electrode tips for each welding guns. Furthermore, the reliance on the resistance welding schemes limits the materials that can be joined together; for example the direct joining of the Aluminium and Steel panels leads to galvanic corrosion, also the fusion welding is not applicable for plastic parts. Even though, more and more adhesive bonding is applied within the automotive industry, it is done on the expense of Metal Inert Gas MIG welding and the mechanical fastening techniques not the spot welding.

- The tack welding step assembles the automobile shell parts together to form the basic vehicle shape, and only then a series of spot welding processes create the permanent joints and the final fit and dimensions of the panels' relative positions. To create the first shape in tack welding, a fixture with the specific vehicle body shape should be used to hold the different panels in the exact relative positions needed, for each of the body main sub-assemblies. If several vehicle models are built on the same line, this will require multiplicity of these fixtures which add cost and precious manufacturing time to replace, transport, and store these fixtures. Different "flexible" and /or "intelligent" fixture designs have been developed by several of the automotive OEMs such as the Robogate system developed by the Fiat Motor Company, the Intelligent Body Assembly 
System IBAS developed by Nissan, the Preciflex system developed by Renault, and the Intelligent Jig Fixture introduced by the Toyota Motor Company. However, these flexible fixturing solutions are not yet perfect, for example the Robogate system has a large footprint that limits its applicability and adoption, while the remaining fixturing solutions with the exception of the Preciflex, still require transporting the un-used pallet or fixture if it is not in use.

- A more integrated solution to the fixturing problem is to incorporate fixturing and clamping reference points and features through the panel shape and geometry, which is created in the stamping process. These clamping features ensure that the panels will only fit one way, the right way.

- The painting process starts by immersing the vehicle shell into cleaning, conditioning and phosphate tanks, in addition to the electro-coat bath. Due to the complicated geometries of the vehicle shell and the large number of holes and gaps in it, even the immersion process can't guarantee a full coverage of the shell surfaces and fill its gaps and crevices. Even though new dip systems are based on rotating the BiW inside the tank to ensure better coverage, such systems are limited by some physical limits, for example the E-Coat coverage is limited by the Faraday's cage effect; hence the soluble paint does not reach inside the tubes and extrusions more distance than its external diameter.

- The current paining process consumes around 60 to $70 \%$ of the total energy within an automotive assembly plant due to the number and the nature of the processes involved. The air conditioning inside the spray booths is the major consumer of electric energy while the curing ovens have the lowest efficiency (around 10 to 20\%) consuming the majority of the fossil fuel requirements. Other major energy expenditures are in the water treatment, because the water is used in capturing the over sprayed paint in the under-booth area, then it passes through a scrubber system to separate the water to go to the treatment facility and the over sprayed paint to accumulate as sludge.

- The final assembly processes are heavily dependent on manual operations which are not only difficult to integrate into the overall production control system but also, require further tooling and fixturing solutions to extend the operators reach and facilitate their operations. This adds further ergonomic considerations and training and liability issues.

The mentioning of the above challenges are meant to show the current manufacturing lines' limitations and major shortcomings, so new manufacturing sequence and processes are proposed to solve some of the above issues. Additionally listing the main limitations of current production lines can serve as a starting point for any new manufacturing systems.

Also, from the above challenges, one can conclude that the current, automotive manufacturing main stations are not well integrated, on the contrary each station work might complicate the sub-sequent ones' operation; for example the complex geometries and holes formed in the stamping process not only limits the paint coverage in the E-Coat baths but also complicates the robotic programming to apply the spray paint layers. Additionally, the different geometries created early on in the manufacturing sequence limit the robotic welders' flexibility and accessibility. The robotic welders' flexibility is limited by the fact that each body style will require a different fixture to hold the different panels in space so that the tack welding process can be applied to determine the vehicle body shape. So the 
proposed manufacturing system will re-consider the sequence of the manufacturing processes to incorporate the ease of manufacturing perspective.

The following section will address new concepts to replace some of the current automotive manufacturing processes to yield a more integrated and dedicated manufacturing sequence that is flexible, with higher value addition per unit time.

\section{New concepts in automotive manufacturing}

\subsection{New manufacturing system, decision making}

The first step in proposing a new manufacturing process, sequence and ultimately a system is to recognize the improvements required and decide on metrics of success so that any proposed system can be benchmarked against the current one. One can extract such objectives and metrics from the discussion in section two to be in following aspects; increasing the flexibility of the production lines, reducing the overall production cost, and increasing the production stability and quality levels. These metrics can be further translated into; (a) reduction in the production lead time, which helps in increasing the production flexibility and reduce its overall cost. (b) Reduce the number of processes and manufacturing operations needed to complete the vehicle build, (c) reduce the manufacturing process complexity level, (d) reduce the re-work and scrap levels to reduce the cost and non-value added work. (e) Increase the production standardization level and facilitate equipment re-configuration for different body styles.

The second step is to prioritize these improvements, by using systematic decision making tools. Such tools include the Quality Function Deployment QFD matrices and the Analytical Hierarchy Process AHP. The QFD is a systematic decision making tool that lists the improvements required as "customer demand" for example, short production lead time, along with a numerical rank to show their priorities. Also, the QFD describes the technical implications of each of these demands on the production line and more importantly on the product; also it explores the positive and negative interactions between these technical implications to help finalize a relative rank of each of the improvements. Figure 1 shows a standard QFD template filled with the current case study specifics, where the above mentioned customer demand are listed on the left hand side and the technical implications or the manufacturing system functional requirements are listed in the corresponding columns. Such technical requirements include; the reduction in parts count, the reduction in setup time, the number of materials selected, the panels' intricate shapes and geometries, consolidation of processes, etc. Also, the inter-relationships between these technical requirements are listed in the top of the QFD matrix. For example, the reduction in number of components has a strong relationship or effect on the reduction in setup time, this is indicated as a score of 2 , which means that any reduction in the number of parts leads to major reduction in the setup time. However, the reduction in variability in panels' dimensions has a negative impact on the technical requirement of avoiding intricate shapes and geometries that is indicated as a score of -1 .

On the other hand the AHP process ranks the different objectives or customer demands based on their performance in achieving the sought goals and objectives. Additionally the AHP is based on straightforward computation that can accommodate qualitative and quantitative metrics and criteria; in the qualitative sense, it decomposes an unstructured problem into a systematic decision hierarchy. It then uses a quantitative ranking through 
numerical numbers and weights in which a pair-wise comparison is used to determine the local and global priority weights and the overall ranking of the alternatives. It is worth mentioning that both QFD and AHP have provided the same results showing that the part consolidation and the use of modular sub-systems are the highest rank metrics.

\subsection{Process perspective}

Previous sub-section indicated that a manufacturing system capable of using modular structures and a common product platform will have the highest potential of meeting the automotive OEMs main objectives of cutting cost, lead-time, and increase the flexibility levels. So the proposed manufacturing system should accommodate these two metrics through process selection and sequence.

To reduce the parts count, one can think of consolidating the body panels by re-designing their stamping dies; for example the body side outer is typically composed of $3-5$ pieces including the A, B, C pillars, the quarter panel, and the fender. Combining these panels into one piece can reduce the parts count, however it impacts the product functionality and design. To illustrate with more words, this consolidation approach can limit the freedom of designers to selectively select different materials for their different locations within the same body panel; for example the fender can be made out of plastic to reduce the vehicle weight, and the B-pillar to be made out of two panels with different thicknesses to serve the different load bearing requirement from each location. So from this discussion, the mere changing of the stamping dies to consolidate the body panels into lesser count is not trivial and can lead to loss of design freedom, in addition this approach alone will lead not only to lesser utilization of the generated engineering scrap but also to higher scrap and offal rates, which in turn translates into higher manufacturing cost. One should also consider the current technologies dependant on the parts count such as the Tailor Welded Blank TWB approach, where different panels in grade or thickness are joined together using laser welding then stamped to form a tailored body panel. In addition the consolidation of parts count based on changing stamping dies add another challenge to the OEM, that is the addition of a more expensive die to develop and validate. Also, at the same time, the body shape is still locked early in the production cycle and the complicated geometries and features are still created before the painting or welding activities.

Based on above discussion, one might consider departing from forming the body panels using the press and die based systems, into more flexible fabrication techniques that allow for more flexibility from product and process perspectives. Such forming alternatives include super-plastic forming, which not only allows for fabricating large and complex shaped panels in single process step, but also it allows for the use of light weight materials such as Aluminium and Magnesium. The super-plastic forming can result into higher elongation from those achievable in typical press stamping, and can reach up to $800 \%$ total elongation. The super-plastic forming is achieved under, high temperature with low forming force and low strain rate; however not all materials can be formed using this technique due to the fact that the super-plastic forming is dependent on the material grain boundary sliding which is only achievable for materials with very fine grain size. Additionally, the super-plastic forming cycle is in the order of hours when compared with the press-stamping, which can achieve the final shape in few seconds. But one should consider all the time expended in the non-value added steps, such stacking and de-stacking 
the different panels and pieces that can be replaced with one super-plastic formed panel. To provide a more descriptive example, one can super-plastic form the whole under-body as one piece that can be made out of Magnesium or Aluminium, while stamping the underbody constitute forming many different Steel pieces that need to be transported, setup and then joined together; so when comparing the two under-body manufacturing methods, the super-plastic forming might offer more advantages and flexibility but at higher cycle time. Another possible forming technique that can be applied for some of the body panels is based on folding the sheet metal using slit and smiles created along the fold line. Even though this forming approach is not suitable for all body panels due to the surface finish requirements, it can eliminate the need for any forming dies in addition it can result in greater flexibility in changing the body style on the fly, because the slits location, number, and shape can be changed through a computer controlled laser cutting machine. Additionally this approach can reduce the engineering scrap and offal by optimizing the cutting process; also this forming approach can be done using different material types. Furthermore, this forming method helps in reducing the part count through integrating the different folds to create different shapes from one cut sheet. It also facilitates transporting the flat cut panels and reduces the efforts needed for stacking and de-stacking.

Industrial Origami Incorporated IOI is pioneering the forming through folding technology, a demonstration of their technology is displayed in figure 2, which shows an instrument panel formed from one piece.

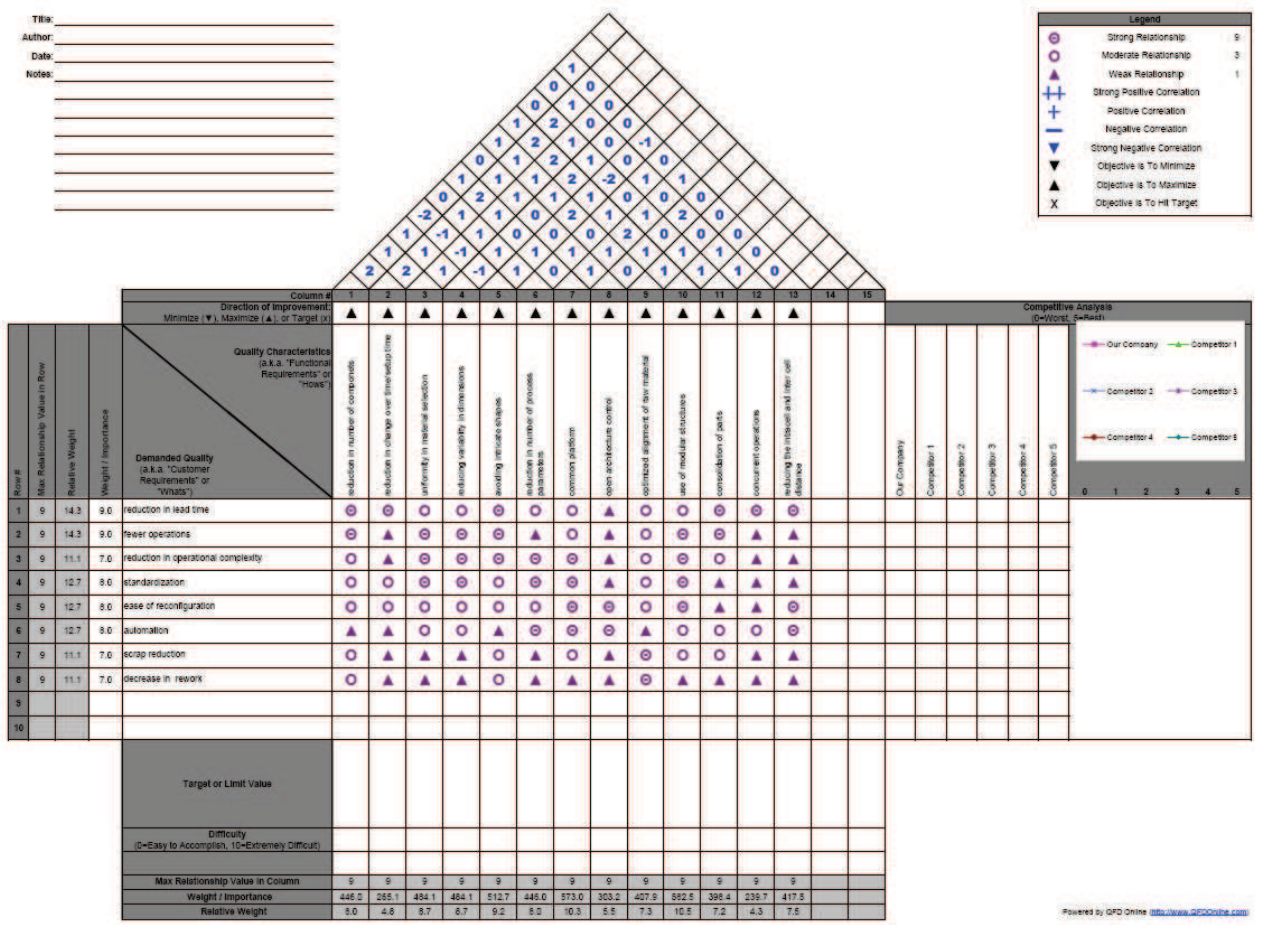

Fig. 1. QFD matrix 
Using the Industrial Origami IOI technique and the super-plastic forming can also present a new potential for facilitating the automobile production by changing its sequence. In more words, an OEM can move the conditioning phase of the painting process to be before the folding step; because it is easier and more efficient to immerse coat flat sheets than complicated geometries; also this will improve the phosphate and E-Coat coverage over the panels. Additionally, the slits and smiles compose referencing and clamping features within the stamping so no additional fixtures are needed to fixate the panels' relative positions. This reduces the overall investment in fixtures and mounts and the production overall lead time, also it improves the flexibility of the joining process and the better utilization of the space floor; because, some of the proposed flexible fixturing systems as the Robogate has a large foot-print as mentioned previously. Additional benefits of the folding-based forming are due to the fact that the panels can be shipped and transported in and out of the plant in flat shape and also reduce the number of joining processes needed to create the different sub-assemblies, which can also be said about the super-plastic formed pieces because it integrates several smaller panels into one.

So, from the above discussion, one can layout a new production sequence to start with conditioning stage of the Steel and Aluminium sheets through immersing it in the cleaning, phosphating baths. Then the forming of the body panels is achieved through super-plastic forming, folding, and press-based forming. The press based forming will be mainly for the exterior panels; such as door outer skins, hood, roof, body-side outer that also incorporate the fenders. The use of super-plastic forming should consolidate several panels to compensate for its slow cycle time, such as the under-body, which should integrate the floor pan, the trunk pan, etc. Any considerations about the effect of the applied coatings on the formability of the material should be analyzed from the frictional interface conditions between the die and the sheet metal. Also, the coating integrity should be tested to ensure that it was not degraded because of the forming process. Even though this arrangement require the use of different forming technologies with different machinery and equipment requirements and expertise, it ultimately focuses on streamlining the overall production by reducing the stamped panels count while at the same time provide several modular subassemblies that can be shared between the different vehicle models.

For the new joining step, it starts by folding the interior components and fixating them relative to each other using the embedded clamping points and features. Then join them to the under-body panels to form a basic module that can be used for different body styles. Then, the body side outer can welded to this module. The body side outer along with the other closure panels (doors, hood, etc) will be the changing panels between the different vehicle models. The design of these panels will incorporate also clamping features to help locate the panels' relative positions in the welding process to avoid the reliance on a dedicated fixturing systems or solutions. After the welding is completed, the BiW will go straight into the new paint area which features spray booths only to provide a single coat of anti-corrosion paint formulation to replace the E-Coat layer, in addition to the sealants and the under-body wax applications, then run the BIW through a curing oven to cure the sealants and the paint all at once, which saves energy and space, in addition to reducing the number of processes. The sprayed paint should also be applied for the internal panels and its colour should be neutral. The use of a curing oven is necessary and can't be easily replaced in the automotive industry because some of the currently used steel grades require baking to add more strength to the 
steel at its fabrication stages; such grades include the Bake-Hardenable $\mathrm{BH}$ grades. The $\mathrm{BH}$ steel microstructure contains small amounts of carbon in solid solution which when heated comes out of the solution to increase the steel strength and dent resistance. Such steels are developed so that the final steel strength and dent resistance meet the functional requirement without having to use a strong steel grade in the stamping stage, which requires more tonnage. The final paint coats, including the top-coat that include the colour pigments, the UV absorbing pigments, and the metallic flakes, in addition to the clear coat, are proposed to be applied in the dealership per the customer demand for colour and finish. This proposal try to further postpone applying the final colour so that the dealerships have greater flexibility in manipulating their car inventory per customer purchasing trends. Additionally, moving the top and clear coats painting outside the automotive manufacturing plant, hence reducing its overall energy consumption, its overall floor space requirements and also, reduce the process count leading to a shorter lead production times.

For the new final assembly area, it should also use modular trim components that can be easily shared between the different vehicle models; also such modules should be designed in terms of its size and shape to fit into the vehicle without the need to remove the doors. This eliminates the need to remove the doors and have them move uselessly around the plant to meet with the vehicle shell at the end of the assembly line.

The proposed manufacturing sequence and processes are selected based on the main two objectives extracted from the QFD and the AHP results that is reducing the number of parts and using more modules. The coming sub-section will discuss the changes and modifications needed to incorporate the suggested transformational changes and processes.

\subsection{Structural and operational issues}

The difference in cycle time between the proposed forming techniques should be first addressed to ensure that the proposed production line functions based on an average takt time. To address this issue, one can use the Value Stream Mapping VSM technique to decide on the adequate buffer levels that will ensure the slow forming methods (super-plastic forming) are not bottle necks, using the minimum Work In Process WIP levels.

One of the tools used in VSM is the implementation of a supermarket at the end of the press stamping operation so that the faster process (press stamping) is producing according to the quantity and type of panels pulled from the supermarket, as controlled and specified by the production and the withdrawal Kanban cards. Additionally, one can enrich the pressstamping with more work content; such as assembling the doors inners and outers and the hood inners and outers. The enrichment of the work content has the added advantage of creating lesser number of stations that are easier to control and can accommodate a cellura base layout. The cellular layout offers better communication schemes and enables people and equipment sharing within the cell leading to better resource utilization and higher flexibility levels to accommodate different product types and volumes. For the super-plastic forming multiple stations might be established to help keep up with short cycle times, in addition to a buffer to further compensate for the cycle time difference.

The above discussed plan not only enables the OEMs to use the super-plastic forming and other forming technologies for some sub-assemblies, but also it establishes lesser workstations that can produce more specialized complete sub-assemblies, that is each workstation adds more value content to the vehicle in continuous fashion without the need for the stacking, de-stacking, and transporting items between smaller stations. 
The new joining line will receive bigger sub-assemblies that can be joined directly to the vehicle under-body; this due to the fact that the cells that used to provide the welding line with the different assembled parts such as; floor assembly, rear-floor assembly, engine compartment, roof cowl, are all shifted to be done in the stamping step. Also, joining certain reinforcements can also be done in the stamping process by using the techniques of In-Die joining. So, a shorter body-weld line is achieved.

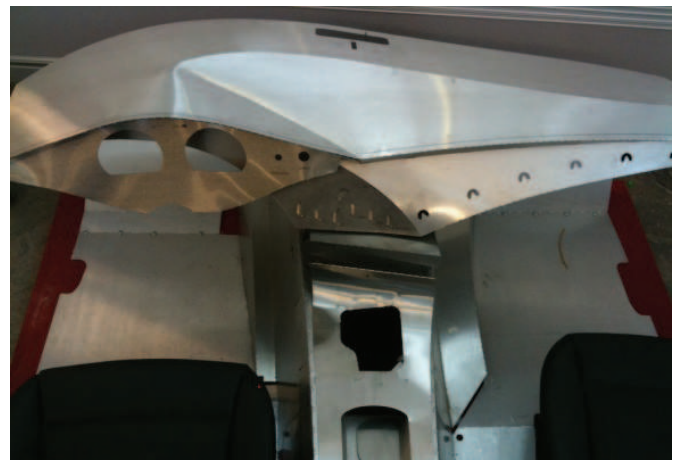

Fig. 2. Folded Instrument Panel

The new paint line layout is much simplified and is composed of; a cleaning station where the $\mathrm{BiW}$ are first cleaned from any accumulated sludge from the weld line using paint friendly detergent formulations. Also, this station can accommodate the sealant and underbody wax applications steps; then the BiW travels through a single spray paint booth to receive an anti-corrosion coat, and then pass through the curing oven. The new paint line has much smaller foot-print because it doesn't have the selectivity bank area that is typically used to change the sequence of the production vehicles so different colour batches can be created; in addition to pulling vehicles for paint defects repair. Also, the immersion process is already shifted and only one curing oven and one spray booth are used.

\section{Discussion and challenges}

To apply the proposed processes and layout into current vehicle designs and OEM facilities, require a collaborative effort between the different manufacturing stations' engineers. For example, paint engineers should work with the stamping engineers to decide on the best way of applying the phosphate coats on the metal sheets, in addition to analyzing the effect of the stamping process on the paint adhesion and integrity. Furthermore, the welding engineers should work with the designers to help embed locating and clamping features into the panel designs to help alleviate the need for locating fixtures and jigs.

Additional efforts are needed from the material scientists to develop new, cheaper Aluminium alloys that can be blow formed in super-plastic forming. Also, equipment supplier should be involved to help in developing faster super-plastic forming machines that can meet the production requirement of the new production line. Additionally, discrete event simulations should be done to optimize the material and content flow through the production shop floor and regular VSM activities should be carried out to ensure the continuous improvement of the production line operation. 


\section{References}

Clarke, C. (2005). Automotive Production Systems and Standardisation, Physica Verlag, 3-79081578-0, Heidelberg

Hitomi, K. (1996). Manufacturing Systems Engineering, Taylor and Francis, 0-484-0323-x, London

Omar, M.; Mears, L., Kiggans, R., \& Kurfess, T. (2009). Organizational Learning in Automotive Manufacturing: A Strategic Choice. Journal of Intelligent Manufacturing, ISSN 0956-5515, DOI 10.1007/s10845-009-0330-6 


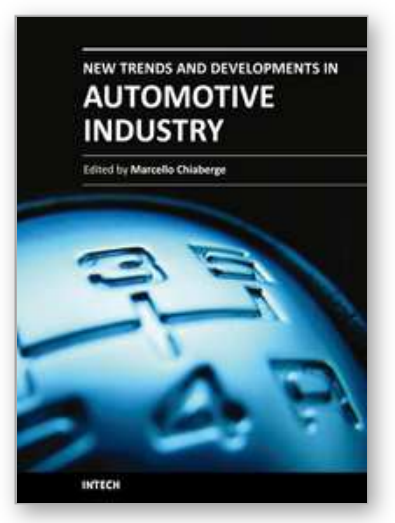

\author{
New Trends and Developments in Automotive Industry \\ Edited by Prof. Marcello Chiaberge
}

ISBN 978-953-307-999-8

Hard cover, 394 pages

Publisher InTech

Published online 08, January, 2011

Published in print edition January, 2011

This book is divided in five main parts (production technology, system production, machinery, design and materials) and tries to show emerging solutions in automotive industry fields related to OEMs and no-OEMs sectors in order to show the vitality of this leading industry for worldwide economies and related important impacts on other industrial sectors and their environmental sub-products.

\title{
How to reference
}

In order to correctly reference this scholarly work, feel free to copy and paste the following:

Mohammad A. Omar (2011). New Concept in Automotive Manufacturing; a System-Based Manufacturing, New Trends and Developments in Automotive Industry, Prof. Marcello Chiaberge (Ed.), ISBN: 978-953-307-999-8, InTech, Available from: http://www.intechopen.com/books/new-trends-and-developments-in-automotiveindustry/new-concept-in-automotive-manufacturing-a-system-based-manufacturing

\section{INTECH}

open science | open minds

\author{
InTech Europe \\ University Campus STeP Ri \\ Slavka Krautzeka 83/A \\ 51000 Rijeka, Croatia \\ Phone: +385 (51) 770447 \\ Fax: +385 (51) 686166 \\ www.intechopen.com
}

\author{
InTech China \\ Unit 405, Office Block, Hotel Equatorial Shanghai \\ No.65, Yan An Road (West), Shanghai, 200040, China \\ 中国上海市延安西路65号上海国际贵都大饭店办公楼 405 单元 \\ Phone: +86-21-62489820 \\ Fax: +86-21-62489821
}


(C) 2011 The Author(s). Licensee IntechOpen. This chapter is distributed under the terms of the Creative Commons Attribution-NonCommercialShareAlike-3.0 License, which permits use, distribution and reproduction for non-commercial purposes, provided the original is properly cited and derivative works building on this content are distributed under the same license. 